\title{
Digital Technologies, Informing Science, and Transformations in Teaching-Learning Processes
}

\author{
Antonio Cartelli, Università degli Studi di Cassino e del Lazio \\ Meridionale, Casino, Italy
}

cartan@unicas.it

\begin{abstract}
The paper first analyzes the changes occurred in everyday individual life for the presence of digital technologies, with a special attention to the use of these equipments in the construction of units of learning, learning environments and for the assessment of learning. The difference between the young students (digital natives) and the teaching-learning experiences based on digital technologies, leads to the proposal of the definition of product digitization for the reported situation. Soon after, the application of the socio-technical approach to educational experiences is discussed and the definition of process digitization is proposed.
\end{abstract}

The analysis ends with the proposal of the use of both the digitization strategies in education, so that students can be more and better involved in educational processes.

At last the revision of the definition of informing science is proposed to consider the effects that digital information and digital process management have on subjects.

Keywords: digital technologies, education, informing science, process digitization, product digitization.

\section{Introduction}

It is today almost obvious to say that digital technologies and the Internet have changed our life. In last decades (since late '70s, early ' $80 \mathrm{~s}$ ), computers evolved and became user friendly due to the introduction of special input devices (e.g., mouse and joystick) and graphics user interfaces (GUIs), but it is probably the introduction and the spreading of digitization and the Internet, that produced the most relevant changes in data acquisition, communication and our life at all. Both the above phenomena forced people to use computers more and more frequently, because most part of the information they sent and received, had to be managed by computers and other digital equipment (Heffernan, 2011).

Before the digital revolution described above, when analogical equipment were progressively substituted by digital instruments, communication technologies and especially mass media al-

Material published as part of this publication, either on-line or in print, is copyrighted by the Informing Science Institute. Permission to make digital or paper copy of part or all of these works for personal or classroom use is granted without fee provided that the copies are not made or distributed for profit or commercial advantage AND that copies 1) bear this notice in full and 2) give the full citation on the first page. It is permissible to abstract these works so long as credit is given. To copy in all other cases or to republish or to post on a server or to redistribute to lists requires specific permission and payment of a fee. Contact Publisher@InformingScience.org to request redistribution permission. ready induced deep changes in mankind. M. McLuhan (1968), stated that media determine the structural features of communication and produce pervasive effects on people imagination, independently from the information they could transport (by using the words of McLuhan, the above sentence can be synthesized with the mot "the medium is the message"). 
Very recently, while using Popper metaphor of the "bad teacher" for television (1996), G. Sartori has proposed the definition of Homo videns (looking man), for his contemporary generation. Sartori observes that children usually stay behind television too many hours, before learning to read and to write, so that they become familiar with the great amount of violence present on television, and predispose themselves to be more violent once adult. Furthermore, Sartori (1997) says that children, and people more generally, when looking at the television receive an imprinting, and he concludes that this is an educational action, more centred on looking and seeing than on acting.

Specifically speaking, when sociology studied the effects of digitization and of the Internet on mankind, the problem of the influence of these digital media on the people arose. M. McLuhan (1989), before all, thought that new media could induce very useful and positive effects on mankind, for example by increasing the level of democracy all over the world, so that a "global village" could be created.

Psycho-technologists, on another hand, suggested deeper changes on human cognition and intelligence by means of the Internet. P. Levy (1996) suggested the construction of "collective intelligences" on the Net, they are the result of high levels of collaboration among people staying connected and look like the result of a single mind; communities of people on the Internet can build group intelligences, these intelligences emerge from the cooperation and competition among the subjects belonging to those communities. De Kerckhove (1996), starts from Lévy ideas and adapts them to the technological environment of computer networks, as a result his attention is centred on the connection of people intelligences for the hitting of a common and unique target, more than on collaboration among individuals. With De Kerckhove the connectivity runs parallel to Lévy's idea of community, but at the same time it opposes to Lévy's idea: "the new medium overcomes the communication of the elements in the message and creates multimedia, and cognitive artifacts". To better describe the effects of digital media and especially the Internet, De Kerckhove introduces the definition of psycho-technologies for them, and modifies McLuhan definition of "global village", he says in fact: "it is no more the village to be global but the people living in it, who have satellite and Internet connections, so that they can reach every place and everyone at any time". As a result, for De Kerchkove, globalization is not a phenomenon pertaining to finance and economy, it is the field of psychology, because it is the expression of mental stages and subjects' perceptions when people are connected on the Net.

More recently P.C. Rivoltella (2006) adopts a new definition for the society influenced by the presence of new technologies, today society is for Rivoltella a "multi-screen society", where the spaces of vision are multiplied, and traditional television is accompanied by computer screens, portable consoles (e.g., Nintendo and Mobile PS), public equipments (like those in stations and airports), palmtops, mobile phones, smart-phones etc. Main result of the visual multiplication depending on the multiple screens is the re-definition of the individuals' seeing, which features are now:

- To be intermittent (it is a mosaic of not contextualized visual stimuli),

- To be mobile (it no more refers to the time passing for what is seen, but it is connected to the looking time of the people who transfer their look from one screen to another one) and

- To be interactive (what is seen is exactly what people likes to see, because it is selected among many different screens).

Furthermore, the multiplication of human seeing acts on at least the following two human dimensions:

- Knowing, which is no more stored and mono-visual, but is shared and multi-access,

- Living, which is no more situated in a physical space but is social (which means: to be in touch with others while being connected on the Internet). 
Rivoltella concludes that there are deep implications for humankind, because the categories of being are much more involved in the above changes than the categories of perception. There is no more contrast between real and virtual experiences (the last ones have always been considered as imaginary, before the last changes), and virtual life is a possible life at all, not less real and concrete than physical life.

As regards learning, Rivoltella's ideas receive a great support from Siemens' proposal of the connectivism as a knowledge paradigm (2005). The Internet is now the metaphor of learning, where every node in the Network can be connected to other nodes, like information, data, images and sentiments. Learning is the process which creates connections and lets the network grow, and it can depend on not human instruments and applications. Among its most relevant features there are:

- Stability of connections, which are essential for permanent learning,

- Ability in finding new connections, which is a very important skill,

- Continuous updating, verification and trustiness of knowledge, which are the main targets in learning activity.

In next sections it will be shown how digital technologies influence the creation of learning environments and, what is more important, how differently learners and teachers have approached learning and education in the digital society.

It is important to recall here that M. Prensky (2001) has been one visionary interpreter of phenomena of the new millennium on this side, because he already remarked the difference between young and elder generations. He called "digital natives" the people born in a world populated of digital technologies, able in using them since their earliest instant of life, and called on the contrary "digital immigrants", those who had to learn the language and the use of new technologies, to face the multiplicity of the contexts of interaction with digital equipments, but did never metabolized them.

The main questions guiding the discussion of the following topics will be:

- Whether technology has been widely used in educational environments what can be said on the compatibility of the experiences people had, with digital natives features?

- Are there experiences on new digital environments, which can be considered more suitable for digital natives?

- What consequences have for informing science the definition, creation and use of new digital educational environments?

\section{Product Digitization in Education: Digital Technologies and Learning Environments}

In this section an attempt is made to give an answer to the first question reported above. The analysis of learning environments starts from formal education, due to the importance that these contexts have on the growth of young generations, but the results from non formal and informal educational experiences, which are important in adult education, are not discarded.

On this side, a special attention is given to the scheme proposed by M. L. Conner (2004). Her analysis of learning environments and the connections existing among themselves are well synthesized in the picture reported below, where the relative increase in the importance of unexpected and informal learning in today society are well showed. 


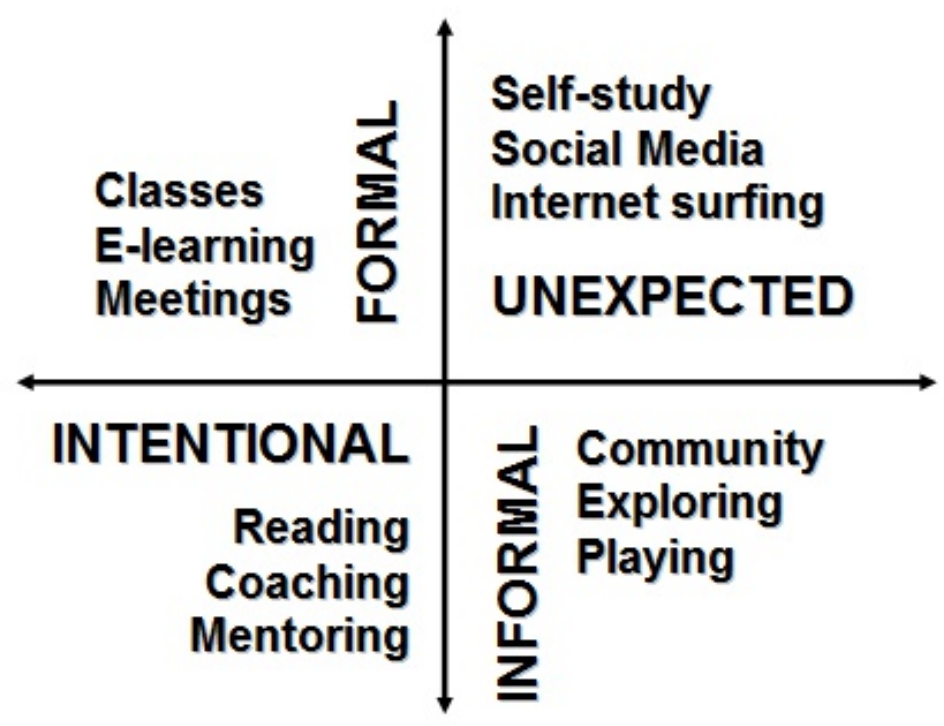

Figure 1 - Map of different learning environments and learning strategies

Undoubtedly the growth of informal education and unexpected learning during last decades can be explained by the spreading of digital technologies.

As regards formal education most part of the involvement of digital technologies is expressed by means of traditional psycho-pedagogical paradigms: behaviorism, cognitivism and constructivism.

In behaviorism, where behavior is more important than the understanding of internal activities and learning is seen as a behavioral change, the leading principles of teaching are: assessment, intervention and evaluation. Almost all behavioral hypotheses used computing to support teachers in their work or to develop self contained learning systems; good examples on this side are CAI (Computer Aided Instruction), CAL (Computer Aided Learning), CAE (Computer Aided Education) Systems, or Test Systems and, more recently, due to the introduction of Artificial Intelligence, ICAI (Intelligent Computer Aided Instruction) systems and ITS (Intelligent Tutoring Systems).

In cognitivism, where learning is viewed as a process of data input, managed in short term memory and coded and stored for long-term recall, knowledge is still considered as external to learner (and learning is the process of internalization of knowledge in the subject). Cognitive theories influenced e-learning by leading teachers to the use of editing and authoring tools in everyday class work. The first step in this revolution, directly involving students in the production of documents, is based on the use of office automation suites (especially word processors, spreadsheets and presentation managers), followed by the use of Hypercard, Flash, HTML editors and Quicktime, which led to the development of simulation environments and educational games (all digitally developed).

Constructivism assumes that learners are not empty vessels to be filled with knowledge, but they must be actively involved in knowledge creation processes. Two different fields of study were developed under the constructivist flag: the interactive and the social. In the first case the process guiding knowledge construction is based on subject's interaction with the external environment. S. Papert (1993), well represents this area of constructivism; he invented the LOGO programming language, by which children were allowed to construct their own knowledge with the Turtle Ge- 
ometry (i.e., it creates one micro-world in which children can explore the learning environment and restructure it or even add new micro-worlds to it). With social constructivism the leading role in learning is played by social interaction inside communities. Relevant contributions in this field have been given by the Laboratory of Comparative Human Cognition (LCHC) (1982), M. Cole (1996), J. Lave and E. Wenger (1991), but the most important results in formal education come from A. L. Brown and J. Campione (1994), who focused on communities of learners. Students, teachers, tutors, and experts contribute to make a community and work together: they analyze previous knowledge, verify and discuss it, and build new knowledge and theories (i.e., they create a learning community, named CoL). Furthermore, the same authors suggested a change in their idea of $\mathrm{CoL}$, and proposed the concept of fostering community of learners (FCL), which is based on a system of interactive activities within a learning environment, where conscious and reflexive works are made (Brown \& Campione, 1996): research, information sharing, and suitable exercises are for the authors the basic elements for the development of reflection and deepen learning. In these environments digital technologies have a special role not only for the storing of information but for expanding subjects communication with synchronous and asynchronous instruments/strategies.

Connectivism, as proposed by Siemens (2005), can be considered the last step in the evolution of learning environments, and has been developed to overcome the difficulties the other paradigms had in explaining learning phenomena in the digital age. In this last paradigm, learning is a process that occurs within nebulous environments of shifting core elements - not entirely under the control of individuals. Learning (defined as actionable knowledge) can reside outside of subjects (within an organization or a database), it is focused on connecting specialized information sets, and the connections that enable us to learn more, are much more important than our current state of knowing. Connectivism is driven by the understanding that decisions are based on rapidly altering foundations. New information is continuously being acquired, and differences between important and unimportant information must be recognized. Some features of connectivism can be found in the teaching experiences of J. S. Brown (2000), who worked with technicians and researchers on training and updating courses for professionals; the main concepts emerging from his work are: 1) the construction of knowledge assets, which make effective learning in a community of practice, 2) the web as a medium for an ecology of learning, where everyone can be producer and consumer of information and knowledge and 3) the construction of a regional learning repository, where a social knowledge is built and made available.

The digital equipments used in the learning environments depicted above and the ways they are used lead to the following remarks:

- Digital technologies are used to manage information; otherwise stated, they are widely involved in the digitization process of retrieving, storing, editing, data and phenomena, - Digital technologies can create virtual environments which simulate the real processes, and the environments the learner interacts with; that is, they digitize the contexts of people actions, but they maintain separated learner and environment, also when they store the data produced by people in the interaction with the context they are immersed in,

- Digital technologies let people communicate, so that they digitize information and transport it from user to user and side by side, but usually they reproduce the behavior of the analogical equipments until now used for communication.

All the above features led the author to think that we are facing a situation of "product digitization", which means:

- A well defined time interval is needed for the description of any learning phenomenon (which remains essentially analogical), 
- Topics, situations and students' answers can be digitized, but there is no real digitization of processes (the evolution of each process is essentially time dependent and is managed with analogical strategies),

- A digital snapshot can be taken for the whole interaction process (user-context) or for its instants at given fixed times, but no digital cyclic process is activated for further developments and data management.

In next section a different perspective for digitization of educational environments and processes will be discussed, and a new definition, that is "process digitization", will be given for it.

\section{Process Digitization in Education}

The viewpoint adopted in this section is the result of the experiences carried out while working on the development of management information systems (MISs) for research and teaching.

The theories supporting these experiences have their roots in the socio-technical theory developed at the Tavistock Institute in London, where the impact of technology on business efficiency and productivity was analyzed. The results of Tavistock's researchers led to the analysis of the fit between the technical sub-system and the social sub-system, which both are needed in corporations, to overcome the difficulties usually met in the implementation of technological systems (mostly for the resistance of the work force), for the achievement of the benefits expected by management.

The features hypothesized for the two sub-systems were (Badham et al, 2000):

- The technical sub-system is a conversion process transforming system inputs into outputs;

- The social sub-system is more than a set of technical control tasks that have to be performed by people. The technical tasks are combined into the individual jobs and the responsibilities assigned to groups.

Recently the importance of subjects' participation in the organization and the weight of social relationships in autonomous or semi-autonomous groups within the organization assigned a leading role to communities of practices (Coakes, 2004). As a result individual, community and organization (societal) levels were hypothesized to have different roles in knowledge construction and development, and the social sub-system in the socio-technical main structure was supposed to be made of three elements, as reported in figure 2 (Cartelli, 2007).

By applying the above ideas special management information systems (MISs), were planned and developed; they implemented the processes used by scholars and researchers in the management of data and information in their studies. Among the most relevant results obtained with MISs there is the detection of the creation and development of an organizational knowledge inside the communities working on the information systems; the features of this knowledge are very similar to those evidenced by I. Nonaka and H. Takeuchi in their studies on Learning Organizations. If all the stages in the SECI model were detected a further stage, called by the author "implementation of the practices by means of the IT/ICT" (Cartelli, 2008), was hypothesized to explain the effect that MISs could have on people.

Figure 3 drafts the cyclic structure emerging from the inclusion of the new element in the SECI cyclic model for knowledge development proposed by I. Nonaka and H. Takeuchi in learning organizations (1995), also if it does not exhaust the connections between individual, community and societal knowledge. 


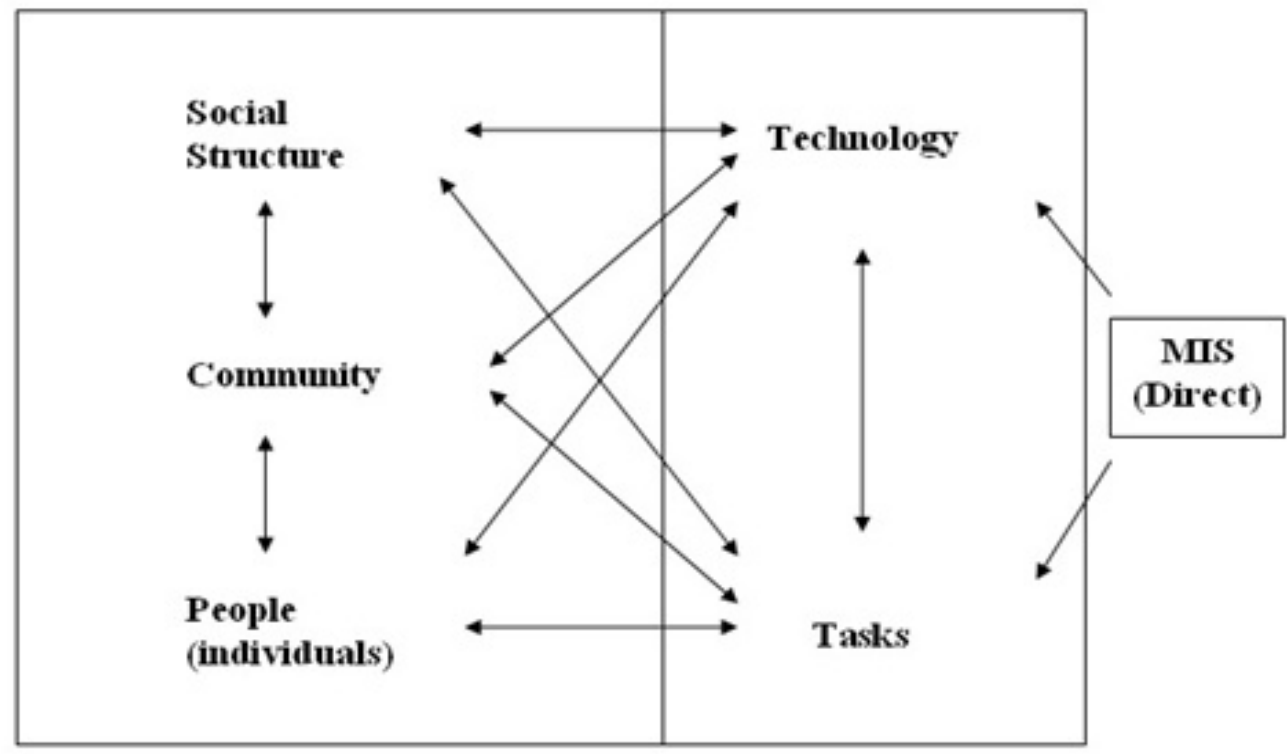

Figure 2 - Graphic representation of socio-technical approach to MIS use

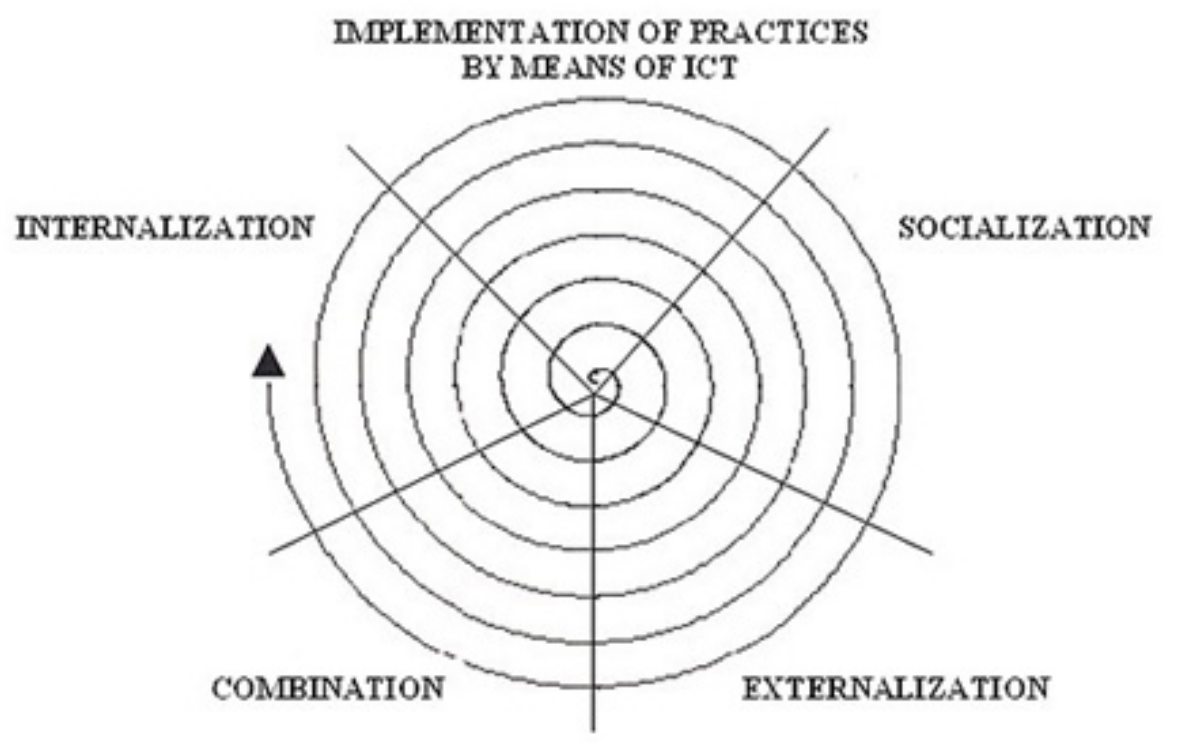

Figure 3 - Individual knowledge, organizational knowledge and their evolution

After the above experiences, the same ideas were applied to the creation of a MIS for the management of teaching-learning activities in a school. The web site supporting that system was called Teaching Transparency Information System (Tetis), to make evident the function of the instruments and processes adopted within it. It was used to create a simulation environment for teachers attending a master course in education; the figure reported below drafts how people were involved in the use of the system and the operations they were allowed. 


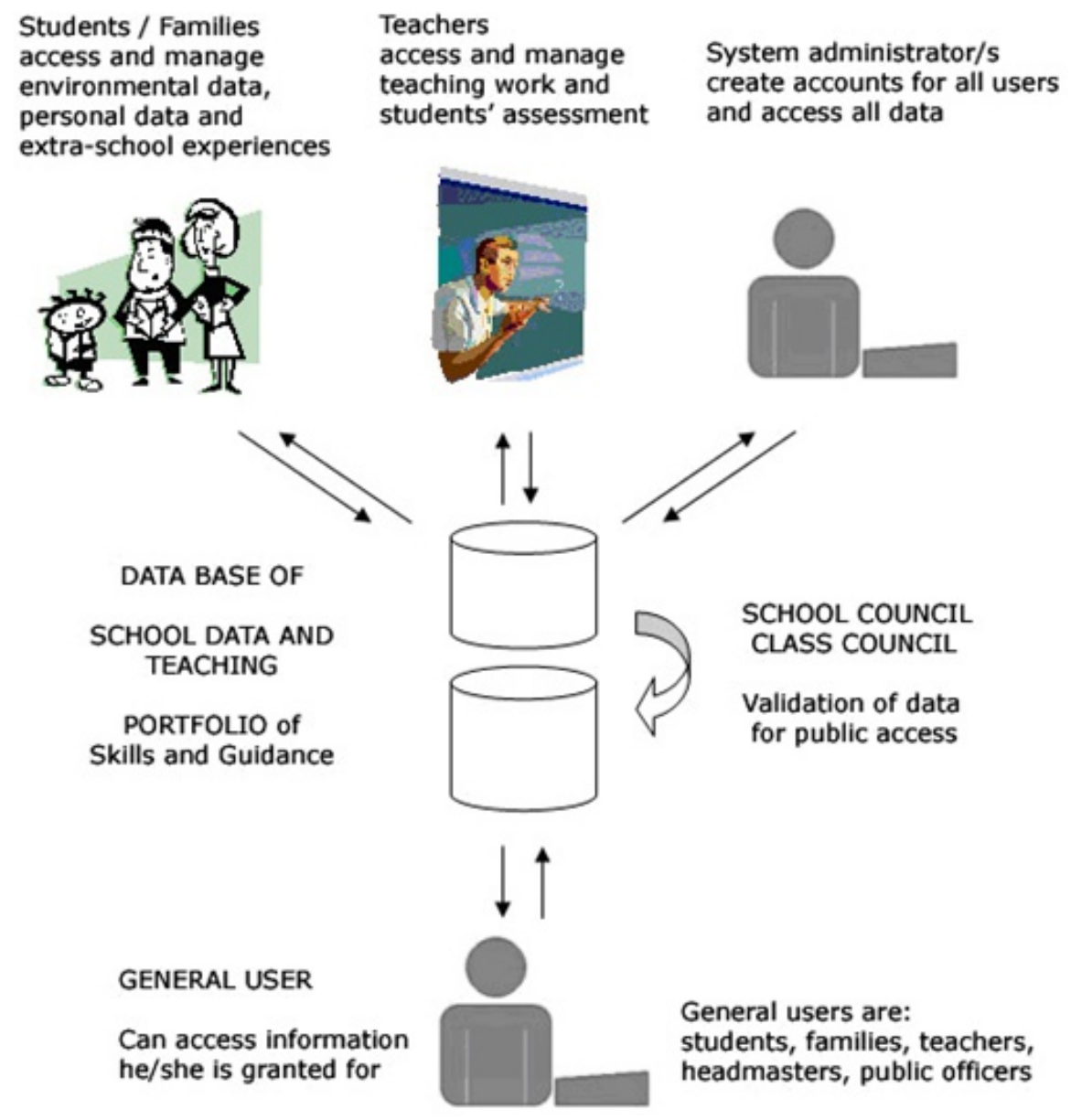

Figure 4 - The TETIS platform for the management of teaching-learning processes

After the first experience described above on TETIS platform (Cartelli, 2005), the system has no more been used till 2010. That year, an agreement was signed by the author with a network of schools, and improvements and changes were introduced in the system to let people use it for the management of everyday teaching-learning activities.

The structure of the database underlying the system was almost the same but the levels of the users accessing the system, the management of information and almost all the features of the system were re-built. The new system has been called Personal Skill Book (PSB).

Figure 4 still represents the way people access the system and the levels of data management inside the system, but what is not evident in the image is the cyclic process by which people produce information, filter it by creating data syntheses, use it to start a new data management process (creation, filtering, synthesis). This process is represented in the figure below. 


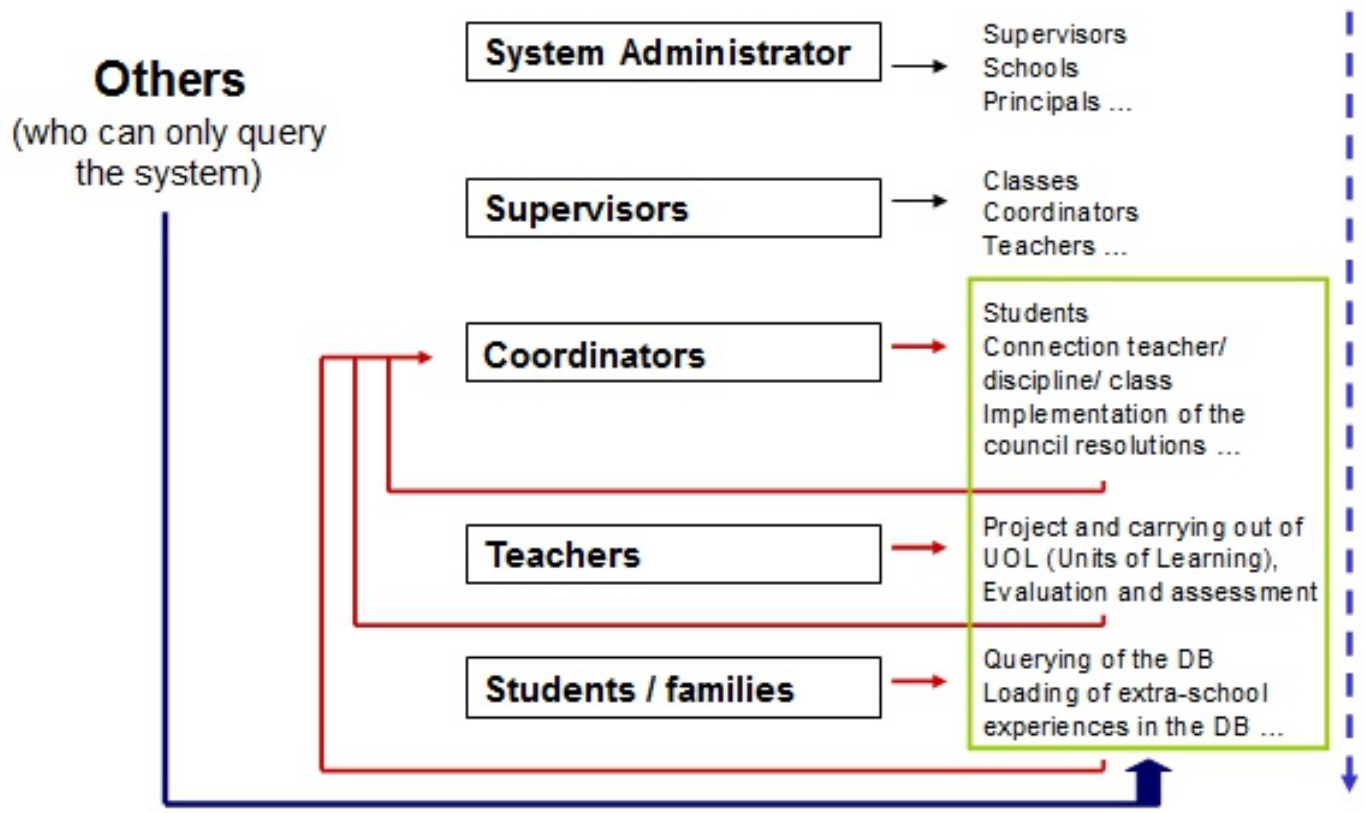

Figure 5 - Synthesis of data management in the PSB system

It is important for what follows to clarify here how the system works (at least for its most relevant functions):

- the system administrator creates the records for the schools, the supervisors and the principals (other functions are planned whether the schools have no people who can work at the level of the supervisor),

- the supervisor creates the records for the classes and the teachers, associates teachers to classes and disciplines and for each class fixes the coordinator-teacher (all these processes are the application of the decisions of the principal and of the school council), he/she also provides the school workers with the learning units approved by the school council all over the school (special education projects etc.),

- the class coordinator creates the account data for students/families, provides the teachers in the class with the learning units approved by the class council, filters the data from teachers and creates the syntheses to submit to the class council for approval,

- every teacher creates his/her own units of learning (by following the scheme: prerequisites, targets, contents, instruments, methods, evaluation and assessment, together with 4 different kinds of taxonomies: cognitive, affective, psycho-motor, socialrelational, which can be associated to the learning unit), uses them to manage everyday teaching work, inputs the scores and the notes for the assessment,

- students / families can access the data that teachers store in the database (concerning the single student), they can also input extra-school experiences of the student which will be evaluated by the class council and, once approved, will be integral part of the student portfolio.

It is obvious from what has been reported until now that the use of MISs is now devoted to the digitization of teaching-learning activities more than the digitization of topics, behaviors, environments.

The PSB system impacts very much the way teachers work, because it modifies at all levels the management of processes: 
- as regards individuals it makes possible:

0 the creation of an e-portfolio of the student,

$\circ$ the creation of an e-portfolio of the teacher,

$\bigcirc$ the resetting of the time communication (especially the school-family time),

0 the resetting of the assessment time for each unit of learning,

0 the instantaneous connection between assessment, recovering and guidance,

- as regards teaching-learning processes it leads to:

$\circ$ the standardisation of the teaching management processes (which are implemented in the system),

0 the resetting of the process evaluation time (which is immediately under observation by all stakeholders and does not need a time interval to be fixed for evaluation),

- easier planning of the recovering actions towards the students with difficulties or problems,

- $\quad$ as regards the whole school:

$\circ$ the same considerations reported for teaching-learning processes can be suggested here,

○ the school adopting the PSB system is made transparent for everyone accessing the system.

As a consequence it can be said that the PSB contributes to create a virtual dimension for teaching-learning processes, which extends the traditional school experience, while making a bridge between digital natives and digital immigrants.

\section{Conclusion and Implications for Informing Science}

In the first section of the paper we have seen that today students are much more different than their teachers, with respect to what happened some decades ago, and their being "digital natives" can be the main reason for the detected differences. Many scholars have already analyzed the youth faculties which have been affected by the changes, i.e. writing and conceptualizing have been increased while memory and learning have been stressed (Ferri, 2011). From those researches emerges also that:

- young people develop non linear and non alphabetical learning models,

- they usually like very much to express themselves,

- they strongly tend to personalization and to information sharing.

As a conclusion teachers must accept the fact that students look at the world in a different way and they have a different representation of that world; by following P. Ferri ideas, the explanation for observed changes can be found in what follows:

- they have been born in a multi-screen society and interact with all these screens since their first birth,

- they always are with their digital communication and expression prostheses,

- they expose themselves on social networks like Facebook or Youtube, and live on each screen in the same way that in the real world,

- $\quad$ at the same time, they listen music and are in touch with their friends by SMS or messenger,

- they don't use manuals and don't need instruments to understand a learning object before using it.

Is today school compatible with the students emerging from the above description?

The answer is only partially positive, because, as showed before, only topics and environments are digitized and can be considered suitable for the "digital natives"; on the contrary, it is very difficult to consider school time suitable for digital natives. Probably, only the whole digitization 
of the school will make them fully compatible with the new generation of students, and the PSB system can help students, families and all stakeholders in this operation.

Furthermore, whether we consider the definition of Informing Science, the discipline that can "provide its clientele information in a form, format and schedule that maximizes its effectiveness" (Cohen, 1999), we ca expect a revision for it, on the basis of the results on the use of product and process digitization. Further research is needed to give an answer to the above question and find possible extensions for a new definition of Informing Science.

\section{References}

Badham, R., Clegg, C., \& Wall, T. (2000). (I) Socio-technical theory. In W.Karwowski (Ed.), Handbook of ergonomics New York: John Wiley. Retrieved on Dec 7th, 2011 from https://www.sonoma.edu/phpbb/viewtopic.php?p=332\&sid=d04e94067bded6533e607232a556a433

Brown, J. S. (2000). Growing up digital: How the web changes work, education, and the ways people learn, change (March/April). Retrieved on Dec 7th, 2011 from http://www.johnseelybrown.com/Growing_up_digital.pdf

Brown, A. L., \& Campione, J. (1994). Guided discovery in a community of learners. In K. McGilly (Ed.), Classroom lesson: Integrating cognitive theory and classroom practice (pp. 229-270). Cambridge, MA: MIT Press.

Brown, A. L., \& Campione, J. (1996). Psychological theory and the design of innovative learning environments: On procedure, principles and systems. In L. Schaube \& R. Glaser (Eds.), Innovation in learning (pp. 289-375). Mahwah, NJ: Lawrence Erlbaum.

Cartelli, A. (2005). Towards an information system making transparent teaching processes and applying informing science to education. Journal of Issues in Informing Science and Information Technology, 2, 369-381.

Cartelli, A. (2007). ICT and knowledge construction: Towards new features for the socio-technical approach. The Learning Organization, special issue "On sharing knowledge: socio-technical approaches", 14(5), 436-449.

Cartelli, A. (2008). The implementation of practices with ICT as a new teaching-learning paradigm. In A. Cartelli \& M. Palma (Eds), Encyclopedia of information communication technology (pp. 413-418). Hershey, PA: Information Science Reference.

Coakes, E. (2004). Knowledge management a primer. Communications of the Association for Information Systems, 14, 406-489.

Cohen E., (1999). Reconceptualizing information systems as a field of the transdiscipline informing science: From ugly duckling to swan. Journal of Computing and Information Technology, 7 (3), 213-219.

Cole, M. (1996). Cultural psychology. Cambridge, MA: Belknap.

Conner, M. L. (2004). Andragogy and pedagogy. Ageless learner, 1997-2004. Retrieved Dec 7th 2011 from http://agelesslearner.com/intros/andragogy.html

De Kerckhove, D. (1996). La pelle della cultura: Un'indagine sulla nuova realtà elettronica. Genoa: Costa \& Nolan.

Ferri, P. M. (2011). Nativi digitali [Digital natives]. Milan: Mondadori.

Heffernan, V. (2011). The digital revolution. La Clé des Langues. Available online on Oct 27, 2011 at http://cle.ens-lyon.fr/93744078/0/fiche pagelibre/

Laboratory of Comparative Human Cognition (LCHC). (1982). Culture and intelligence. In R. J. Sternberg (Ed.), Handbook of human intelligence. Cambridge, MA: Cambridge University Press.

Lave, J., \& Wenger, E. (1991). Situated learning. Legitimate peripheral participation. Cambridge, MA: Cambridge University Press. 
Lévy, P. (1994). L'Intelligence collective. Pour une anthropologie du cyberespace. Paris: La Découverte.

McLuhan, M., \& Powers, B. (1989). The global village. New York: Oxford University Press.

McLuhan, M., \& Quentin, F. (1968). Il medium è il messaggio [The medium is the message]. Milan: Feltrinelli.

Nonaka, I., \& Takeuchi, H. (1995). The knowledge-creating company: How Japanese companies create the dynamics of innovation. New York, NJ: Oxford University Press.

Papert, S. (1993). The children's machine. New York, NJ: Basic Books.

Prensky, M. (2001). Digital natives, digital immigrants. On the Horizon, 9(5, October). MCB University Press.

Rivoltella, P. C. (2006). Screen generation. Gli adolescenti e le prospettive dell'educazione nell'età dei media digitali. Milan: Vita e Pensiero.

Sartori, G. (1997). Homo videns. Televisione e post-pensiero. Rome: Laterza.

Siemens, G. (2005). Connectivism: A learning theory for the digital age. International Journal of Instructional Technology and Distance Learning, 2(1).

\section{Biography}

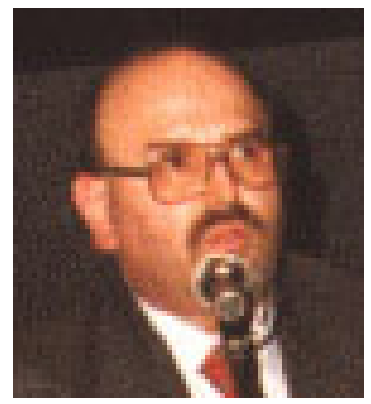

Antonio Cartelli has passed a national competition for associated professorship in Experimental pedagogy. He manages the Laboratory for Technology of Education and Knowledge Management and the Centre for ICT and on line teaching in the Faculty of Humanities at the University of Cassino - Italy. Among his interests are: misconceptions, mental schemes, Information Systems for research and teaching, Web Technologies in teaching research and their everyday application for the improvement of teaching and learning. He is also author of many papers and books concerning the themes he is interested in. 